\title{
SOME STUDIES IN FONDANT MAKING
}

\section{BY MARY STEPHENS CARRICK}

The work to be reported in this paper was undertaken with two points in view: first, to establish a set of directions for making fondant whereby a standard product could always be obtained; and second to explain as far as possible the principles of the process involved. Fondant is made by heating sugar with water and acid, cooling the syrup, and then beating it vigorously. During the heating a portion of the sugar is inverted. It is usually assumed that, if one starts with a given amount of sugar and heats until a given boiling point is reached, the concentration of the final solution is fixed definitely; but this is not necessarily true because the boiling point will vary with the amount of invert sugar present. If the mixture were brought up sufficiently slowly to the final temperature, it would contain only invert sugar. If it is brought up very rapidly, it will contain a relatively small amount of invert sugar. Since relatively small changes in the amount of invert sugar have very marked effects on the quality of the fondant, it is evident that two people may get different results, depending on the size and shape of the pan and on the number and type of burners used. As a matter of fact the difference of boiling point with varying amounts of invert sugar is unimportant under ordinary conditions with the kind of thermometer ordinarily used.

In all the experiments ordinary tap water was used. This may be either hot or cold. The hot water simply dissolves the sugar more quickly. However, cold water was used in all of this work because that is always available.

Various acids were tried at first. Vinegar (acetic acid), lemon juice (citric acid) and cream of tartar (potassium acid tartrate). Cream of tartar was found to be the most desirable, first, because it gave a better texture to the finished product; second, it is a solid form and its composition is more constant than that of vinegar or lemon juice. The amount 
of acid used can, therefore, be measured more accurately. Third, the tartrate is easier to keep and inexpensive. For these reasons, cream of tartar was the acid used in all of these studies.

\section{Proportion of Ingredients}

One cup of sugar by measure was used in all experiments. The average weight of this amount of sugar is about 2 Io grams. To this weight of sugar varying amounts of water were added.

In the following tables the time of cooking was 15 minutes and the maximum temperature reached was $116^{\circ} \mathrm{C}$ :

TABLE I-SHOWING THE INFLUENCE OF VARIOUS AMOUNTS OF WATER

\begin{tabular}{|c|c|c|c|c|c|c|}
\hline \multirow{2}{*}{$\begin{array}{c}\text { Serial } \\
\text { No. }\end{array}$} & \multirow{2}{*}{$\begin{array}{l}\text { Sugar } \\
\text { Wt. in } \\
\text { grams }\end{array}$} & \multicolumn{2}{|c|}{ Water } & \multirow{2}{*}{$\begin{array}{l}\text { Total } \\
\text { measure } \\
\text { before } \\
\text { cooking }\end{array}$} & \multicolumn{2}{|c|}{ After cooking } \\
\hline & & $\begin{array}{l}\text { Wt. in } \\
\text { grams }\end{array}$ & Measure & & Wt. grams & Measure \\
\hline I & $2 \mathrm{I} 3 \cdot 2$ & 251.6 & I cup & $I^{1 / 2}$ cups & 224.9 & $2 / 3$ cup \\
\hline 2 & 210.7 & I 80.2 & $3 / 4 \operatorname{cup}$ & $\mathrm{I}^{1 / 4}$ cups & 228.3 & $2 / 3$ cup \\
\hline 3 & 210.2 & II 5.4 & $1 / 2$ cup & I cup & $225 \cdot I$ & $2 / 3$ cup \\
\hline 4 & 210.6 & $59 \cdot 9$ & $1 /{ }_{4}$ cup & cup & $229 \cdot 5$ & $2 / 3$ cup \\
\hline
\end{tabular}

In the above table 0.30 gram of cream of tartar or $1 / 8$ teaspoonful, and I cup of sugar, which varied slightly in the number of grams, were used in all four cases.

These data show that no matter what the amount of water used at the beginning, the total measure after cooking is the same. The differences in the total weight was also very slight. Subtracting the weight of sugar from the total weight after cooking, gives the amount of water in the finished product. The average amount of water present in the fondant is seen to be 15.7 grams, or about one tablespoonful.

Since there is a constant amount of water remaining in the fondant, obviously any difference in the resulting texture must be due to the hydrolysis caused by varying amounts of water and not in the final quantity of water present as 
such. The speed of inversion is proportionate to the concentration of hydrogen ions present.

A quantitative determination of serial No. I made with one cup of water was found to contain 7.88 percent invert sugar, while in No. 2 , using $3 / 4$ cup of water, 6.28 percent of invert sugar was formed. The product made from one cup of water was very sticky, due to too much hydrolysis. The most desirable amount was $3 / 4$ cup of water and this gave a smooth, creamy texture to the fondant. Smaller amounts of water as shown in Nos. 3 and 4, were unsatisfactory because they rendered the material too stiff and hard. A smaller amount of water than $3 / 4$ cup can be used if a longer time is allowed and the temperature during cooking is lowered. However, the purpose was to establish a minimum time and regulate the other conditions accordingly. The time element will be discussed later.

Using $3 / 4$ cup of water, one cup of sugar, cooking for $x_{5}$ minutes and not exceeding a temperature of $116^{\circ} \mathrm{C}$, different amounts of cream of tartar were added. These amounts varied from $1 / 1$ to one teaspoonful. Less than $1 / 8$ teaspoonful did not cause sufficient hydrolysis to give the desired texture. More than $1 / 8$ teaspoonful proved undesirable, first, because it formed too much invert sugar, resulting in a very sticky product; and second, because a presence of more than $1 / 8$ teaspoonful of acid gave a disagreeable acid taste to the material. Under the standard conditions mentioned above, $1 / 8$ teaspoonful of cream of tartar gives 6.28 percent invert sugar which amount seems to be the correct proportion to give the optimum taste and texture. If the amount of acid is increased, the hydrolysis is markedly increased. When $1 / 4$ teaspoonful of cream of tartar was used 9.6 percent invert sugar was formed as compared with 6.28 percent invert sugar with $1 / 8$ teaspoonful of acid.

In this connection it is interesting to note that a type of fondant can be made without the use of any acid. However, it is much less desirable than when the acid is added, for a number of reasons. First, because it requires a very much 
longer time of cooking to secure enough hydrolysis to give it a creamy texture. While the creaminess increases with the length of cooking, it is too slow to be practical. Fondant cooked for an hour to $116^{\circ} \mathrm{C}$ without acid was much less creamy than when cooked for ${ }_{15}$ minutes with $1 / 8$ teaspoonful of acid. When cooked for 15 minutes at $116^{\circ} \mathrm{C}$ without acid, only 0.45 percent invert sugar was obtained. Under the same conditions with $1 / 8$ teaspoonful of acid, as already noted, 6.28 percent invert sugar was produced.

In the second place, non-acid fondant forms crystals while cooking. These crystals make lumps in the material which do not disappear on standing.

The third objection to fondant made without acid is its taste. The small amount of cream of tartar makes a less surfeiting substance than one in which there is no acid present.

In the fourth place, the lack of acid prevents the fondant from being kept to as good an advantage. This is true because it does not acquire smoothness on standing. This question will be taken up later under the change of texture on standing.

\section{Method of Cooking}

The ingredients in the proportions already established were placed in a container and stirred over a flame until melted. This stirring was a precaution against caramelization of the sugar in the bottom of the pan before the water penetrates the sugar. After the syrup began to boil, however, it was not stirred since the agitation might cause the mass to crystallize. Again, stirring would bring the concentrated sugar solution in contact with the sides of the vessel higher up than the boiling syrup. This higher temperature of the vessel would cause crystals to form by the constant drying out of the mixture. The process of boiling does this to a certain extent. Should the crystals; formed on the sides of the container, drop into the boiling syrup as it becomes more concentrated or should they be dislodged in pouring the cooked fondant 
over them into a plate, it would cause large, coarse crystals to form.

There are three ways in which crystal formation during cooking may be kept down to a minimum. First, the boiling at the beginning should be slow. Second, the cover should be kept on the vessel for the first three minutes. The steam will then dissolve the crystals as fast as they form. The best way, however, is to make a swab by wrapping a small piece of cheesecloth smoothly around a fork. Dip this into cold water and wipe down the crystals formed. Care should be taken not to stir the boiling liquid with the fork.

If in spite of these precautions some crystals have accumulated around the sides of the pan, the hot syrup should be strained through a fine sieve as poured out. This should prevent the growth of crystals in the cooling mixture.

A number of different temperatures for cooking fondant were used to determine, if possible, the optimum degree. The material was cooked from I I $2^{\circ} \mathrm{C}$ to $124^{\circ} \mathrm{C}$, allowing a difference of $2^{\circ}$ in each case. At $I 12^{\circ} \mathrm{C}$ the fondant was found to be too soft and sticky to use. This is caused by the presence of too much water. As the temperature was raised the fondant became harder and drier. At $\operatorname{II}^{\circ} \mathrm{C}$ it seemed to give the more desirable texture. At this point about a tablespoonful of water remained in the mixture, as has been pointed out. It seemed better to get the additional softness of the final product from further hydrolysis rather than by the use of more water. With a standard temperature the amount of hydrolysis can be easily regulated by the length of time allowed for the syrup to reach that temperature. The disregard of this last point is the chief cause of failure in fondant making. The popular idea has been that it was entirely a question of concentrating the liquid and that a definite temperature implied a definite result.

In the following table, showing the length of time of cooking, the time was counted from the point at which the mixture was boiling rapidly, or when the thermometer registered $100^{\circ} \mathrm{C}$. 
Table II-Showing Length of Time of Cooking

Sugar $=\mathrm{I}$ cup

Water $=3 / 4$ cup

Cream $0:$ tartar $=1 / 8$ tablespoonful

Temperature $=\mathrm{I} I 6^{\circ} \mathrm{C}$

\begin{tabular}{|c|c|c|}
\hline $\begin{array}{l}\text { Serial } \\
\text { No. }\end{array}$ & $\begin{array}{l}\text { Time in } \\
\text { minutes }\end{array}$ & Results \\
\hline I & 7 & Very sweet, smooth, but stiff \\
\hline 2 & IO & $\begin{array}{l}\text { Less swe:t, more creamy, easy } \\
\text { to handle and only slightly } \\
\text { stiff }\end{array}$ \\
\hline 3 & I5 & $\begin{array}{l}\text { More plastic than above; not } \\
\text { too sticky to work and very } \\
\text { desirable }\end{array}$ \\
\hline 4 & 20 & $\begin{array}{l}\text { More creamy than No. } 3 \text {, too } \\
\text { soft to work }\end{array}$ \\
\hline 5 & 25 & $\begin{array}{l}\text { Creamier than No. } 4 \text { with in- } \\
\text { creasing softness }\end{array}$ \\
\hline 6 & 30 & $\begin{array}{l}\text { Creamier than No. } 5 \text {, with still } \\
\text { more softness }\end{array}$ \\
\hline
\end{tabular}

The above data indicate that the optimum length of time for cooking is $5_{5}$ minutes. Seven minutes used in the first determination was the minimum length of time in which the $116^{\circ} \mathrm{C}$ could be reached. The gas burner employed contained 44 holes. On analysis 3.2 percent invert sugar was found to be present. This fact explains the sweetness of the taste. Invert sugar is less sweet than cane sugar but the amount here is too small to influence the taste.

The stiffness of the product is also accounted for by the limited amount of hydrolysis. Comparing Nos. I and 3 , it is seen that the latter, as mentioned, gave 6.28 percent invert sugar, showing almost twice as much hydrolysis. Increasing the time to twenty minutes, 8.14 percent invert sugar was found to be present. This proved to be much too soft to work. A longer time still increased the stickiness. Discarding then, all periods of time longer than fifteen minutes as undesirable, tests were run for every two minutes between seven and fifteen minutes in order to study the intermediate products. Nine minutes and less gave fondant too stiff. 
From eleven to fifteen minutes, there was very slight difference in the resulting texture.

From these observations it was concluded that any period of time from ten to fifteen minutes would give excellent results, the fifteen-minute period being slightly preferable.

By standardizing the time and temperature factors in the cooking process, that is, allowing fifteen minutes for the thermometer to reach $\operatorname{Ir} 6^{\circ} \mathrm{C}$, the variable conditions of the size and material of the container and the kind of burner, are eliminated. In the work reported here the burner described above, was turned on a little more than half cock.

After cooking, the syrup was allowed to stand in the pan until all bubbles disappeared from the surface. It was then poured into a plate to cool. The bubbles may cause crystallization. In a readily soluble substance like sucrose any decrease in temperature increases the saturation. Hence, checking the temperature by immediately removing the syrup from the stove and pouring it out while still full of bubbles, would favor crystallization.

The fondant could remain in the pan in which it was cooked and cool there, except for the time gained by more rapid cooling when poured in a shallow dish or plate. In the latter there is also liable to be less waste since it is easier to collect the fondant from a plate than from a deeper vessel. But in any case it should be allowed to cool gradually. Sudden cooling may cause spontaneous crystallization of the undesirable type.

It is necessary to beat the mixture to secure crystallization. This bears out the statement of Young ${ }^{1}$ that a solution may be cooled to a temperature noticeably below its saturation temperature without the appearance of crystals of the solute and that mechanical impact is necessary to produce crystals. The stirring or beating acts in this capacity.

7. In the subsequent table, various lengths of time of beating are shown at temperatures beginning at $20^{\circ} \mathrm{C}$ and reaching $70^{\circ} \mathrm{C}$. Above $70^{\circ} \mathrm{C}$ the crystals were so undesirable 
that no data were recorded. The different temperatures were readily obtained by stirring the mixture over a water bath.

TABLE III-Temperature OF BeAting

\begin{tabular}{l|c|c|c|c|c}
\hline Temperature & $\begin{array}{c}\text { Time } \\
\text { Minutes }\end{array}$ & Temperature & $\begin{array}{c}\text { Time } \\
\text { Minutes }\end{array}$ & Temperature & $\begin{array}{c}\text { Time } \\
\text { Minutes }\end{array}$ \\
\cline { 2 - 4 } $70^{\circ} \mathrm{C}$ & 12 & $70^{\circ} \mathrm{C}$ & 4 & $70^{\circ} \mathrm{C}$ & 2.5 \\
$65^{\circ} \mathrm{C}$ & 3 & $65^{\circ}$ & 3 & $65^{\circ}$ & 2 \\
$60^{\circ}$ & 10 & $60^{\circ}$ & 3 & $60^{\circ}$ & 2 \\
$55^{\circ}$ & 7 & $55^{\circ}$ & 3.5 & $55^{\circ}$ & 3 \\
$50^{\circ}$ & 5 & $50^{\circ}$ & 3 & $50^{\circ}$ & 3 \\
$45^{\circ}$ & 3 & $45^{\circ}$ & 6 & $45^{\circ}$ & 3 \\
$40^{\circ}$ & 5 & $40^{\circ}$ & 6 & $40^{\circ}$ & 5 \\
$35^{\circ}$ & 7 & $35^{\circ}$ & 4 & $35^{\circ}$ & 10 \\
$30^{\circ}$ & 13 & $30^{\circ}$ & 15 & $30^{\circ}$ & 13 \\
$25^{\circ}$ & 23 & $25^{\circ}$ & 23 & $25^{\circ}$ & 23 \\
$20^{\circ}$ & 20 & $20^{\circ}$ & 20 & $20^{\circ}$ & 20
\end{tabular}

It was observed that the higher the temperature the more granular the mixture, due to the hastening of the chemical reaction by the heat. An attempt will not be made to explain why the crystals at the higher temperature formed so quickly. The data, however, show this to be the case. In general the cooler the mixture, the longer the time of beating, and the more creamy the texture. There appeared little difference between the temperatures of $30^{\circ} \mathrm{C}$ and $40^{\circ} \mathrm{C}$. The slight gain in texture at $30^{\circ} \mathrm{C}$ was not commensurate with the length of time necessary to obtain them. At $35^{\circ} \mathrm{C}$ good results were obtained in a shorter time, but they could hardly be distinguished from those obtained at $40^{\circ} \mathrm{C}$ in a still shorter time. Considering that it only took five minutes to get crystals when stirred at $40^{\circ} \mathrm{C}$ and considering the almost equally desirable texture produced, this temperature is believed to be the optimum.

The lower temperature gave good results with an increasingly smooth texture, but in these instances too much time was employed. The colder the fondant the stiffer the syrup becomes and, hence, the more difficult to beat as well as requiring more time. 
To determine the best manner of beating, three methods were tried. In all cases the conditions were the same, excepting the way in which the syrup was beaten. In the first method a wooden spoon was used in beating; in the second, a wooden spoon was used in stirring, making a vigorous circular movement; the third was the "cut in" method. A silver knife was used for this. The "cut in" process consists merely in scraping up the whole mass, folding it over and then cutting it through with a knife. This treatment was suggested by the recommendation of one writer who insisted that it was the only way in which an excellent product could be secured.

Nine determinations of each of the above methods were made. In treatments one and two there was no difference in the texture. In number three, however, in every case the texture was more granular and lacked creaminess. This seemed due to the slower and less vigorous movement employed. The first method was the quickest.

It was observed that in beating the thick syrup small bubbles of air were incorporated into the mass by the process of stirring. An infinitesimal number of these always accumulated before the crystallization began. There are two possible theories, on which to explain this phenomenon. First, there may be a momentarily increased saturation of the surface film, so that the solution is supersaturated with respect to the smallest possible sugar crystals. In the second place, the air incorporated may contain dust. This may start the crystallization. If this is true, dust must have the power of increasing the concentration in the film around the dust particle.

\section{The Effect of Kneading}

The usual procedure in making fondant is to beat it until the mixture is stiff and then knead with the hands into a soft, moist mass. Some experiments were carried out to show the necessity of kneading.

From the same cooking of fondant, one-half was kneaded and the other half placed away without kneading at all. On examination of the unkneaded material it was found to be 
much more sticky than the kneaded. To overcome this stickiness it was cooked to a higher temperature with the intention of removing a little more water. The syrup was cooked to I $18^{\circ} \mathrm{C}, 120^{\circ} \mathrm{C}$, and $122^{\circ} \mathrm{C}$ and allowed to cool to $40^{\circ} \mathrm{C}$. It was then beaten. It was found that the higher temperature did not remove the stickiness in the unkneaded fondant. At $122^{\circ} \mathrm{C}$ it was too hard to work.

Later it was discovered that all the stickiness could be "kneaded out" after it had been put away for some time, if it was then kneaded. The product resulting from delayed kneading was identical with the product secured by immediate kneading. The conclusions from these observations were that if the fondant is kneaded before being placed away, little kneading is required when it is worked up later; if put away immediately after beating without kneading, very much more kneading will be necessary at the time of using. In either case, the kneading is necessary to remove the stickiness. It is merely a choice as to when the kneading shall be done, whether before or after standing.

The question then arose in regard to the amount of beating necessary when the fondant was placed away without kneading. The table below gives some data on this point in which the beating was continued from two to five minutes.

TABLE IV-Showing the EFfect of the Length of Time of BEATING ON TEXTURE

'Time of cooking $=15 \mathrm{~min}$.

Cooking temperature $=116^{\circ} \mathrm{C}$

Temperature of beating $=40^{\circ} \mathrm{C}$

\begin{tabular}{c|c|c}
\hline $\begin{array}{c}\text { Serial } \\
\text { No: }\end{array}$ & $\begin{array}{c}\text { Time of } \\
\text { beating }\end{array}$ & Results \\
\hline I & 2 & $\begin{array}{c}\text { Very hard; a mass of syrup and } \\
\text { large crystals }\end{array}$ \\
\hline 2 & 3 & $\begin{array}{c}\text { Excellent product but required } \\
\text { longer kneading }\end{array}$ \\
\hline 3 & 4 & $\begin{array}{c}\text { As above but required less } \\
\text { kneading }\end{array}$ \\
\hline 4 & $\begin{array}{c}\text { Harder than No. } 3 \text { but required } \\
\text { same kneading }\end{array}$
\end{tabular}


In this table the following materials were used in all instances: $\mathrm{r}$ cup of sugar; $3 / 4$ cup of water; $1 / 8$ tablespoonful of cream of tartar.

From these data it seems better to beat at least four minutes before pouring into a jar, if the material is first to stand without kneading. If beaten less than three minutes unsatisfactory results are obtained.

\section{The Change of Texture on Standing}

It has long been observed that fondant becomes more soft and creamy on standing. This fact was first accounted for by postulating that fondant takes up moisture. However, since the same effect is obtained when the material is kept in a moisture-proof container, evidently there must be some other explanation.

On the theory that the larger crystals are cemented together by the smaller ones, any change of temperature would tend to change the texture. If the temperature is raised, the smaller ones dissolve and the larger ones fall apart. This is equivalent to saying that the mass becomes more plastic. Proof of this theory was obtained by a very simple experiment. A square of loaf sugar was placed in a saturated sugar solution in which some sugar crystals were still left in the bottom of the flask. On standing for a week the loaf fell apart. This phenomenon is analogous to the change occurring in the texture of the fondant. The dissolving out of the small cementing crystals leaves the relatively larger crystals free to easily slip about in a syrupy mass. This also accounts for the ultimate disappearance of all lumps present in the freshly made fondant.

In the work on the influence of kneading and not kneading, it was observed that after three or four minutes of beating, the creamy mass was poured into a glass jar, it immediately became very stiff and hard. This was due to an interlocking of the crystals. On standing over night it became very sticky. This was because of the dissolving out of the cementing crystals as described above. The crystals which remain, not hav- 
ing been broken up by any kneading at the time of putting the fondant away, were necessarily larger than the largest ones in the kneaded material. Hence, there was more syrup medium to the surface of the crystals in the unkneaded fondant than in the kneaded fondant in which the crystals were smaller. And consequently, the unkneaded fondant would become even more plastic on standing than the kneaded. The "kneading out" of this excess plasticity is explained on the basis that kneading simply increases the surface of the crystals by breaking them up so that there is relatively less syrup medium to the surfaces; therefore, a less sticky mass. By this kneading, or increasing the surface of the crystals, all the stickiness can be removed from the unkneaded fondant. By the same process any small amount of stickiness found in the fondant, at the time of making, may be removed.

If the fondant is very sticky and longer kneading is required it is better to use a board and a knife as a breaking up of crystals evolves heat. As the fondant becomes warm it is necessary to let it stand long enough before proceeding further, since the heat tends to dissolve the crystals. It is not very desirable to "let it stand" in the hands. Stickiness due to the presence of too much water or to excess of hydrolysis cannot be "kneaded out."

\section{Analysis of Fondant}

In making fondant according to the preceding data, one would start with 2 Io grams (I cup) of sugar, I80.2 grams $(3 / 4$ cup) of water and 0.3 gram ( $1 / 8$ teaspoonful) of cream of tartar. This mixture should be cooked for 15 minutes until it reaches a temperature of $116^{\circ} \mathrm{C}$. On this basis the finished material should contain 15.7 grams of water, I3. 188 grams of invert sugar, $196.8 \mathrm{I} 2$ grams of sucrose and 0.30 gram of cream of tartar. This is assuming, however, that the cream of tartar acts as a catalyst and further, that 6.28 percent invert sugar is formed by the process and that this amount remains the same. At this temperature with the small amount of water present invert sugar is not likely to undergo further decomposition. 
Knowing the above proportions, theoretically, it ought to be possible to obtain fondant by mixing these three ingredients together. The practical impossibility comes in not being able to dissolve this large amount of sugar in so small an amount of water. However, if sucrose is ground in a mortar to the degree of fineness of the crystals in fondant and to this is added commercial glucose in the proportion to give the one tablespoonful of water present in fondant, a fondant-like material can be made. The composition of commercial glucose is as follows: Water, I9 percent; glucose, 38.5 percent; dextrin, 42 percent; and ash, 0.5 percent. It can readily be seen from this that it would require about five tablespoonfuls of commercial glucose to keep the water content correct for one cup of sugar. This proportion was tried and a product was secured very much like fondant in texture, but the presence of the dextrin gave it a gum-like taste. This can be partly overcome by the addition of the usual amount of acid.

The question of making fondant without the use of heat is, indeed, an interesting one. Further work along this line may prove of considerable practical importance.

The summary of the foregoing study can best be stated in the recipe for fondant making given below.

\section{Recipe for Fondant}

I cup of sugar; $3 / 4$ cup of water; $1 / 8$ teaspoonful of cream of tartar.

\section{Directions for Making Fondant}

I. Put sugar, water and cream of tartar in a container and stir over heat until melted.

2. Carefully remove all crystals from the side of the pan.

3. Allow 15 minutes for the syrup to reach a temperature of $116^{\circ} \mathrm{C}$.

4. Remove from the heat without jarring and let stand until all bubbles leave the surface.

5. Pour slowly into a shallow platter.

6. Let stand until cooled to $40^{\circ} \mathrm{C}$.

7. ${ }^{1}$ Beat for at least 3 minutes after which it can be

1 If fondant is put away without kneading, this must be done when ready to use. 
poured into a glass jar, covered closely and put away, or beaten until stiff.

8. Knead into a soft, moist mass and put away into a tightly closed glass jar and allow to stand at least 24 hours.

\section{Acknowledgment}

The author wishes to gratefully acknowledge her indebtedness to Professor W. D. Bancroft, Department of Chemistry, under whose immediate direction this work was done. His many helpful suggestions are incorporated throughout this study. Thanks are also due Professor Flora Rose, of the Home Economics Department, for her practical suggestions; Professor G. W. Cavanaugh, Department Agricultural Chemistry, who kindly made the determinations of the invert sugar present; and to Professor T. R. Briggs, Department of Chemistry, for the reading of the manuscript. 